\title{
REMINISCENCIAS CANÓNICAS EN LA PRAXIS PROCESAL CORDOBESA DURANTE LA SEGUNDA MITAD DEL SIGLO XIX, ARGENTINA
}

Pamela Alejandra Cacciavillani*

\begin{tabular}{l|l}
\hline RECEBIDO EM: & 18.11 .2020 \\
\hline APROVADO EM: & $\mathbf{2 . 1 2 . 2 0 2 0}$ \\
\hline
\end{tabular}

* Doctora en Derecho y Ciencias Sociales, Universidad Nacional de Córdoba, Argentina. Docente Investigadora. Profesora en Escuela de Derecho y Ciencias Sociales Universidad de Monterrey (UDEM), México. Candidata a Investigadora Nacional por el Consejo Nacional de Ciencia y Tecnología (CONACYT), a partir de enero del 2020. Correo electrónico: pamela.cacciavillani@udem.edu.mx ORCID: 0000-0002-9482-2659 
- PAMELA ALEJANDRA CACCIAVILLANI

- RESUMEN: La segunda mitad del siglo XIX trajo, para el entonces territorio cordobés, una serie de cambios relevantes en términos legales. No obstante estas transformaciones, en el ámbito procesal se advierte la pervivencia de legislación y prácticas propias del orden indiano. Considerando la fuerte relación existente entre derecho y religión en el régimen colonial y su continuidad durante la segunda mitad del siglo XIX, este trabajo pretende analizar una práctica concreta: la solicitud de excomunión en un juicio civil. Con ese objetivo, se indagará en el rol de las penas espirituales dentro de la jurisdicción civil, señalando así los límites entre esta y la jurisdicción eclesiástica. En esta dirección, para divisar las transformaciones y límites entre ambas jurisdicciones proponemos un estudio comparativo entre un texto de práctica forense y las leyes procesales provinciales.

- palabras clave: Prácticas procesales. Excomunión. Derecho.

\section{REMINISCÊNCIAS CANÔNICAS NA PRÁXIS PROCESSUAL DE CÓRDOBA DURANTE A SEGUNDA METADE DO SÉCULO XIX, ARGENTINA}

- Resumo: A segunda metade do século XIX trouxe para o ainda então território de córdoba, Argentina, uma série de transformações relevantes em termos legais. Inobstante tais transformações, pode-se perceber a sobrevivência da legislação e das práticas típicas da ordem indiana no campo processual. Considerando a forte relação entre direito e religião no regime colonial e a sua continuidade durante a segunda metade do século XIX, este trabalho busca analisar uma prática específica: o pedido de excomunhão em julgamento civil. Com este objetivo em mente, o presente estudo investigará o papel desempenhado pelas penas espirituais dentro da jurisdição civil, apontando, assim, os limites entre esta e a jurisdição eclesiástica. Neste sentido, a fim de discernir as transformações e limites entre ambas as jurisdições, propomos um estudo comparativo entre um texto de prática forense e as leis processuais provinciais.

- Palavras-chave: Práticas processuais. Excomunhão. Direito. 


\section{CANONICAL REMINISCENCES IN PROCEDURAL PRAXIS IN} THE SECOND HALF OF THE 19TH CENTURY IN CORDOBA

\section{ARGENTINA}

- ABSTRACT: The second half of the 19th century brought with it a series of more than relevant legal transformations in the Argentinean territory of Cordoba of the time. Notwithstanding these incipient changes, one can see the survival of practices and legislation typical of the Indian order remaining on the legal-procedural field. Taking into consideration, on the one hand, the strong relationship between law and religion in colonial law and, on the other hand, the survival of the latter during the second half of the nineteenth century, this paper seeks to analyze a specific practice: the request for excommunication in a civil trials. It will thus investigate the role of spiritual penalties within civil jurisdiction. This analysis will contribute to the study of the limits between civil and ecclesiastical jurisdiction at the end of the 19th century. In this direction, in order to discern transformations and boundaries between the two jurisdictions, we propose a comparative study between a text of forensic practice and provincial procedural laws.

- KEYWords: Procedural practices. Excommunication. Law.

\section{Introducción}

La segunda mitad del siglo XIX constituye el momento en que las empresas codificadoras lograron cierto éxito en el territorio argentino, entendiendo por esto, la sanción y posterior entrada en vigencia de diversos cuerpos normativos; no así su efectividad. No obstante el marcado interés que la codificación, tanto civil como penal, despertó y todavía despierta en las investigaciones en historia del derecho, el estudio de la experiencia codificadora en el ámbito procesal es un asunto pendiente. Sobre esta situación, Levaggi señaló hace ya algunos años el escaso interés “por el conocimiento, con criterio histórico-jurídico, de la codificación procesal en las provincias”․ Si bien, a partir de los

1 A. LEVAGGI, La codificación del procedimiento civil en la Argentina, Revista Chilena de Historia del Derecho 9 (1983) 211-47, p. 211. 
numerosos y prolíficos estudios que en el marco de la historia de la justicia ${ }^{2}$ han reconstruido las prácticas procesales en sus contextos de producción, el análisis jurídico de la irrupción de los instrumentos normativos procesales continúa siendo una problemática que demanda atención.

En buena medida, la finalidad de este artículo es contribuir con esta agenda pendiente en un punto específico: los límites entre la jurisdicción civil y la eclesiástica. Para ello, analizaremos un tipo de práctica procesal concreta: la solicitación de excomunión en un expediente por tierras, medida que demandaba necesariamente la actuación conjunta de la jurisdicción eclesiástica y secular. Como bien lo ha señalado Agüero, para el ámbito criminal del antiguo régimen, "Los remedios espirituales y las penas seculares debían cooperar para mantener a los hombres en el camino de la virtud ${ }^{3}$.” Pese a los conflictos que emergían "no faltaban ocasiones en las que las autoridades eclesiásticas y seculares operaban conjuntamente para resolver cuestiones criminales ${ }^{4}$.

Si bien nuestro análisis tiene como objeto una cuestión en el ámbito civil, partimos de la cooperación señalada por Agüero y de la evidencia de excomuniones en este ámbito ${ }^{5}$. Nuestro caso de estudio reflejaría no solo la labor conjunta de ambas jurisdicciones en la segunda mitad del siglo XIX sino también el poder que recaía en "la amenaza religiosa ultraterrena" ${ }^{6}$. El uso de este tipo de mecanismos demanda una reflexión en torno al valor de la religión en los primeros años de la segunda mitad del siglo XIX así como de la percepción que los magistrados de la jurisdicción civil tenían respecto de la poca efectividad de las penas seculares. Máxime cuando el tribunal que solicitaba la colaboración era la Excelentísima Cámara de Justicia de la provincia de Córdoba.

Para llevar adelante este análisis se propone como caso de estudio un juicio llevado ante la Excelentísima Cámara de Justicia de la provincia de Córdoba. En este proceso

2 A.AGÜERO, Tradición jurídica y derecho local en época constitucional: El Reglamento para la Administración de justicia y polícia en la campaña de Córdoba, 1856, Revista Historia del Derecho, 41 (2016) 1-43.; D. BARRIERA (comp.), Justicia y fronteras. Estudios sobre historia de la justicia en el Río de la Plata. (Siglos XVI-XIX), Universidad de Murcia / Servicio de Publicaciones / Red Columnaria, Murcia 2009, 244 pp.; D. BARRIERA, Historia y Justicia. Politica y sociedad en el Río de la Plata (Siglos XVI-XIX), Prometeo, Ciudad Autónoma de Buenos Aires 2019, 742 pp.; N. BERALDI, La implementación de la justicia de paz en la provincia de Córdoba. ¿Claves tradicionales en un mundo liberal?, Revista Historia del Derecho, 53 (2017) 1-22.; M .A. CORVA, Constituir el gobierno, afianzar la justicia. El poder judicial de la provincia de Buenos Aires (1853-1881), Prohistoria Ediciones / Instituto de Investigaciones de Historia del Derecho, Rosario 2014, 364 pp.

3 A. AGÜERO, Castigar y perdonar cuando conviene a la república. La justicia penal de Córdoba, siglos XVII y XVIII, Centro de Estudios Políticos y Constitucionales, Madrid 2008, 488 pp.,p. 139.

4 A. AGÜERO, Castigar y perdonar cuando conviene a la república..., cit., 139.

5 S. BENITO MOYA, “Nadie le quite pena de excomunión mayor”. Escritura expuesta y confesionalización en Córdoba del Tucumán durante la colonia, Documenta \& Instrumenta - Documenta Et Instrumenta, 18 (2020) 11-40.

6 A. AGÜERO, Castigar y perdonar cuando conviene a la república..., cit.,135. 
por tierras se enfrentó el pueblo de indios de Quilino contra Don Juan Manuel Carranza. Su marcada extensión temporal, de 1856 a 1872, permite apreciar la construcción de un orden jurídico que se bifurca en dos escalas: la nacional (con los códigos de fondo) y la provincial (con la normativa procesal). Simultáneamente, a lo largo de sus fojas se advierte la transición hacia un nuevo horizonte legal y "el paso de una sociedad tradicional, de unanimidad religiosa, que concibe la no diferenciación de esferas (espiritual-temporal, civil-religiosa) a una sociedad que comienza a diferenciarlas mediante un lento proceso de secularización"7 . Este último aspecto, se materializa en el caso de estudio a partir de la solicitud de una pena eclesiástica concreta y su devenir: la excomunión, según lo establecido en la normativa tridentina. En ese sentido, la invocación del Concilio de Trento como fuente normativa dentro de la causa revela "la vigencia de prácticas que introducían en los procesos judiciales a autoridades y normas de carácter religioso"8. Pese a la solicitud de la medida, la falta de concreción de la misma revelaría la pérdida de efectividad de las penas espirituales en un contexto de transición jurídica.

\section{Penas espirituales en un juicio por tierras}

En la historia jurídica son conocidos los casos en los que "la Iglesia proporcionaba un auxilio espiritual a la justicia secular para ayudar a su eficacia”. ${ }^{9}$ La aplicación de penas espirituales, tanto en el ámbito canónico como fuera de él, da cuenta que el “derecho y religión han concurrido durante un tiempo a la conformación de un mismo sistema compulsivo de ordenación social”" ${ }^{\prime 10}$. A esto se suma que en la normatividad vigente en la América colonial y en la independiente "el Derecho era considerado como uno de los elementos de ordenación de la vida social, junto a la Religión y a la Moral"11. Estos elementos, propios de la tradición jurídica hispánica, rigieron igualmente en el Derecho

7 M. GALLARDO, Clero secular y territorialización parroquial en la diócesis de Córdoba, 1875-1925 Prácticas y poder pastoral en el marco del proceso de romanización de la Iglesia y modernización del Estado, Universidad Nacional de la Plata, Facultad de Humanidades y Ciencias de la Educación, Secretaría de Posgrado, La Plata 2016, 942 pp., p. 100.

8 P. CACCIAVILLANI, De propiedad comunal a propiedad individual. El régimen jurídico de la propiedad en Córdoba (1871-1885).Tesis de doctorado, Facultad de Derecho y Ciencias Sociales,Universidad Nacional de Córdoba, Argentina 2018 p. 74.

9 A. AGÜERO, Las penas impuestas por el Divino y Supremo Juez. Religión y justicia secular en Córdoba del Tucumán (Siglos XVII y XVIII), Jahrbuch für Geschichte Lateinamerikas, 46 (2009) 203-30, 212.

10 B. CLAVERO, Religión y Derecho. Mentalidades y Paradigmas, Historia Instituciones Documentos, 11 (1984) 67-92, p. 88.

11 T. TAU AnZOATEgUi, El Jurista en el Nuevo Mundo. Pensamiento. Doctrina. Mentalidad, Global Perspectives on Legal History, Max Planck Institute für europäische Rechtsgeschichte, Frankfurt 2016, 270 pp., p. 26. 
Indiano e incluso se aprecian, desde una perspectiva histórica, como una "verdadera fuerza [...] en los siglos XVIII y XIX cuando se produjo el avance de las corrientes secularizadoras ${ }^{12}$.

Dentro de las diversas intervenciones divinas que la justicia eclesiástica ofrecía a la justicia secular se encontraba la figura de la censura. En su célebre obra Instituciones de Derecho Canónico Americano, Donoso definió a la censura como "una pena eclesiástica medicinal, por la cual se priva al hombre bautizado, delincuente y contumaz de la participación de algunos bienes espirituales”13. El carácter eclesiástico de la sanción se explica a partir del hecho de que solamente podía ser impuesta por la Iglesia a quien estuviera bautizado con la finalidad de enmendarlo, de allí la referencia a lo medicinal. Donoso continúa explicando que al ser una pena que "supone pecado" y una cierta contumacia implícita, se advierte el “desprecio a la autoridad de la Iglesia” ${ }^{14}$. Finalmente, la privación que conlleva la sanción recae sobre lo que dispensa la Iglesia, como por ejemplo: los sacramentos, los sacrificios, la jurisdicción eclesiástica, los sufragios y los beneficios.

En el contexto de este género de penas eclesiásticas, se divisaban tres especies: la excomunión, la suspensión y el entredicho. La primera de ellas, solicitada como auxilio en el juicio de tierras en el que intervinieron los indios de Quilino en Córdoba en el año 1866, se materializaba cuando "el cristiano es [era] separado de los bienes comunes, en cuanto entraña [ba] y supone [nía] la comunicación con los demás fieles”15.

\section{Los indios de Quilino vs Don Mario Antonio Carranza}

En 1866, en el juicio contra Don Mario Antonio Carranza, Doña Juana Quinteros, comparte y apoderada del pueblo de Indios de Quilino, frente al extravío de un cuerpo del expediente alegó el:

[...] “muy grave perjuicio de la causa publica e inseparable para mí [si] particularmente” [y resaltó que este] "es [era] el caso en que la Iglesia a requisición de VE o de cualquier magistrado encar-

\footnotetext{
12 T. TAU ANZOATEGUI, El Jurista en el Nuevo Mundo..., cit., 26.

13 J. DONOSO, Instituciones de Derecho Canónico Americano, Imprenta y librería del Mercurio, Valparaíso 1848, 818 pp., p. 407.

14 J.DONOSO, Instituciones de Derecho Canónico Americano..., cit., 407.

15 J. DONOSO, Instituciones de Derecho Canónico Americano..., cit., 407.
} 
gado de administrar justicia fulmine excomunión contra los sustractores, encubridores [...] de expedientes"16.

La solicitud de este auxilio espiritual continúa, ya que la apoderada del pueblo de indios de Quilino expresó que no existía otro medio que le permitiese recuperar el expediente y, por ende, el perjuicio tanto público como privado, se perpetuaba. Frente a este status quo Doña Juana Quinteros solicitó a VE:

[...] requerir al Exmo Señor Obispo Diocesano, para que previa las mociones y solemnidades de derecho fulmine excomunión Mayor contra los expresados si no de devuelven dicho expediente sustraído o no avisen en forma quien o donde haya sido ocultado ${ }^{17}$.

De la lectura de la fuente se desprende la necesidad de este auxilio por parte de la justicia civil, ya que no había otra forma de recuperar el expediente; también, es posible advertir la solicitud de intervención de una autoridad específica -el Obispo Diocesano- y la aplicación de una pena determinada: la excomunión mayor. Esta, a diferencia de la menor, "separa a un pecador del cuerpo de la Iglesia, y le priva de toda comunión eclesiástica"18. Esto significa que quien fuera objeto de esta pena no podía "recibir ni administrar los sacramentos, ni asistir a los oficios divinos, ni ejercer ninguna función eclesiástica”19. Sobre las causas que debían acreditarse para dar lugar a una excomunión mayor no había una regla especial que las determinara.

No obstante esta falta de claridad, el motivo por el cual Juana Quinteros solicitó esta sanción es bastante claro: el expediente había sido robado y no le quedaba "otro medio para poder recabar el predicho expediente que ha [bía] desaparecido" ${ }^{20}$. Emplear cartas de excomunión con la finalidad de recuperar cosas robadas era en sí "un antiguo dispositivo canónico que se usaba desde tiempos medievales para cobrar deudas o recuperar cosas perdidas ${ }^{21}$. A partir de un estudio de los concilios castellanos entre los siglo XIII y XV, Torres Jiménez sintetizó y condensó en cinco apartados los motivos de las

16 Archivo Histórico de la Provincia de Córdoba (en adelante, AHPC), Esc. 2, Leg. 182, 1872, Exp. 1, fj.135.

17 AHPC, Esc. 2, Leg. 182, 1872, Exp. 1, fj. 135.

18 Diccionario de Derecho Canónico arreglado a la Jurisprudencia Eclesiástica Española Antigua y Moderna, Librería de Rosa y Bouret, París 1853, 1113 pp., 516.

19 Diccionario de Derecho Canónico..., cit., 516.

20 AHPC, Esc. 2, Leg. 182, 1872, Exp. 1, fj.135.

21 A. AGÜERO, Las penas impuestas por el Divino y Supremo Juez..., cit. 223. 
censuras $^{22}$. Es bajo el tercero de estos, denominado "ciertos pecados relacionados con la vida social" que encontramos "la malicia de los abogados"23. Aquí es viable considerar tanto las prácticas típicas de dilación procesal como también la sustracción de los expedientes.

Frente al pedido de Doña Quinteros la Excelentísima Cámara ordenó que fuera la peticionante quien ocurriera ante la curia eclesiástica, puesto que el tribunal consideraba que "[...] a vuestra excelencia [el Obispo Diocesano] corresponde fulminar dicha excomunión mayor previas las mociones de derecho [... $]^{24}$. Si bien la cámara consideraba como competente para imponer la pena al obispo diocesano, antes de su intervención el expediente fue cursado a otro funcionario: el fiscal eclesiástico. Normalmente en cada Diócesis se encontraba presente un fiscal "a quien corresponde defender los intereses comunes de la Iglesia, patrocinando con celos sus derechos e informando siempre que, por los jueces eclesiásticos, se le pida informe"25. En el contexto de la justicia eclesiástica este funcionario además de ser "el procurador del obispo y el encargado de representarlo de una manera permanente en la defensa de los intereses de la iglesia” le corresponde “inquirir y reprimir los crímenes cometidos en la jurisdicción episcopal”26.

Conforme a la división jurisdiccional de la época, la diócesis correspondiente al pueblo de indios de Quilino era la de Córdoba. Quien se encontraba actuando como fiscal eclesiástico en ese entonces era Emiliano Cabanillas ${ }^{27}$, el que gozaba de ese cargo desde 1858. Como bien lo señala el promotor fiscal de la Audiencia episcopal quien se desempeñara en ese cargo “debía ser hombre versado en derecho” lo que implicaba que previamente "hubieran obtenido grados en filosofía o teología" ${ }^{28}$. En el caso de Cabanillas, este promotor obtuvo su grado en derecho canónico en la Universidad de Córdoba, en el año 1855.

22 Los tópicos propuestos por la autora son: a) atentado contra los bienes y la jurisdicción de la Iglesia, b) Ataque al clero y res sacrae, c) ciertos pecados relacionados con la vida social, d) ciertos pecados contra la disciplina cristiana y moral y e) pecados contra la creencia. M. R. Torres Jiménez, El castigo del pecado: excomunión, purgatorio, infierno, en Los Caminos de la Exclusión, en E. López Ojeda (Coor.), La Sociedad Medieval: Pecado, Delito y Represión, Instituto de Estudios Riojanos, Logroño 2012, 245-307, 260.

23 M. R. Torres Jiménez, El castigo del pecado..., cit. 261.

24 AHPC, Esc. 2, Leg. 182, 1872, Exp. 1, fj. 139.

25 J. LIRA. Prontuario de los Juicios o tratado de los procedimientos judiciales, Librería Central de Mariano Servant, Santiago de Chile 1895,70 .

26 N. DELLAFERRERA, Ministros y auxiliares de la justicia eclesiástica en Córdoba (1688-1888), Revista de Historia del Derecho, 25 (1997) 151-182, 158.

27 Don Emiliano se desempeñó como rector del colegio Montserrat y profesor de Derecho Canónico en la Universidad de Trejo, actualmente Universidad Nacional de Córdoba. Ver: P. P. CABRERA, Ex-alumnos célebres de la Universidad de Córdoba. Miguel Calixto Del Corro, Revista De La Universidad Nacional De Córdoba, 1 (2013) 3-109, 5. 
La respuesta del fiscal al pedido de excomunión fue negativa, puesto que "los monitorios o cartas de censura solo las concede el derecho in subsidium"29. En términos procesales, esto significaba que la censura procedía siempre que no existieran, o bien se hubieran "agotado las vías legales para averiguar la verdad sobre el paradero de la cosa perdida que las motiva y cuando esta misma es de considerable valor non alias quam ex re non vulgari”30 ${ }^{30}$. En este punto es importante detenernos en las citas en latín, no solo porque reafirman que estamos frente a "un agente de nivel cultural alto [y] con formación eclesiástica" ${ }^{\sharp 1}$, sino también porque permite identificar los textos normativos que son empleados como fuente del derecho. En este caso, si bien la cita en latín no está acompañada de referencias explícitas, pudimos establecer que se corresponde con una formulación normativa del Concilio de Trento ${ }^{32}$.

La cita de Cabanillas fue extraída de la sesión XXV, capítulo III, del decreto de reforma que establecía que cuando las excomuniones se fulminan con la finalidad de "manifestar alguna cosa [...] o por cosas pérdidas o hurtadas [...] se han de conceder por cosas no vulgares y después de examinada la causa con mucha diligencia y madurez por el Obispo"33. El fiscal valoró la conducta procesal de la solicitante y manifestó "que parece haber practicado las diligencias del caso" ${ }^{\text {"34 }}$. Efectivamente, la apoderada de los indios ya había solicitado al escribano de la causa que se expresara sobre la ubicación del expediente. No obstante el previo requerimiento acreditado, el fiscal se refiere a la práctica, a la costumbre, a lo que comúnmente se realiza en estos casos, destacando que la situación es "tan grave y de suyo tan delicado"35.

La remisión a la costumbre era [y es] algo propio y característico del derecho canónico ya que este "reconoce una equiparación de fuerza normativa entre ley y costumbre [...] Dicho en otras palabras, la costumbre tiene fuerza de ley"36. La interpretación que el fiscal hizo de la costumbre motivó a "requerir por segunda vez a los Escribanos a fin

29 AHPC, Esc. 2, Leg. 182, 1872, Exp. 1, fj.140.

30 AHPC, Esc. 2, Leg. 182, 1872, Exp. 1, fj. 140.

31 A. AGÜERO, Las penas impuestas por el Divino y Supremo Juez..., cit. 213.

32 Esta identificación fue posible ya que en la intervención del reverendo obispo diocesano, este cita de manera expresa la normativa del Santo Concilio de Trento.

33 CONCILIO DE TRENTO, El Sacrosanto y Ecuménico Concilio de Trento, traducido al idioma castellano por Ignacio López de Ayala con el texto latino corregido según la edición publicada en 1564, Imprenta de Don Ramón Martin Indar, Barcelona 1847, 440 pp., Sesión XXVI, Capítulo III, 396. AHPC, Esc. 2, Leg. 182, 1872, Exp. 1, fj. 140.

35 AHPC, Esc. 2, Leg. 182, 1872, Exp. 1, fj. 140.

36 J. OTADUY, Las fuentes del derecho canónico, en J. P. ALCOCER MENDOZA (Coor.), Temas Actuales de Derecho Canónico, Universidad Nacional de México, Instituto de Investigaciones jurídicas, México 2016, 201-220., 215. 
de que informen por segunda vez si se hallan o no en sus archivos los autos perdidos"37. Pero adecuarse a la costumbre, que en este caso significaba cursar un segundo requerimiento, no era una garantía de la prudencia de la censura ya que el mismo fiscal señaló que "el valor de los autos cuya restitución se solicita [...] queda [...] al prudente arbitrio del prelado"38.

Recurrir al prudente arbitrio del prelado es un recurso propio del derecho canónico, orden en el que "No hay condenas generales ni aplicaciones generalizadas de la regla canónica, sino una aplicación dúctil, conducida por las circunstancias específicas, ajena a un rigor formalmente igualitario" 39 . Debido a la imperante finalidad instrumental propia de este derecho como "a las finalidades pastorales que arbitra la sagrada jerarquía - se puede llegar hasta su elusión". ${ }^{40}$ Justamente, fue esta elusión “del superior eclesiástico de no aplicar la norma en el caso concreto (relaxatio legis) ${ }^{311}$ la conducta que se advierte en las siguientes fojas del expediente.

Tiempo después, el 3 de julio de 1866 el obispo se expresó, desde el palacio episcopal, rechazando la solitud de excomunión. Pero este no fue un rechazo concluyente ya que se indicó que nuevamente debía requerirse al escribano por el expediente. En el caso de no encontrar los documentos, el Obispo solicitó: "tráiganse los autos para proveer lo que hubiere lugar" ${ }^{42}$. Esta forma de razonamiento refleja el carácter dúctil e instrumental de las normas canónicas, especialmente, el denominado derecho canónico humano ${ }^{43}$. Es justamente aquí donde se percibe en esa "flexibilidad su primera señal identificadora: la sagrada jerarquía - a la que compete el momento de aplicación”44. En este caso, la jerarquía del obispo “aplicará o dispensará, atenuará o revalidará según las circunstancias en las que la regla general aterriza y se concreta, en conformidad con cuanto exige la ratio legis ${ }^{45}$.

37 AHPC, Esc. 2, Leg. 182, 1872, Exp. 1, fj. 140.

38 AHPC, Esc. 2, Leg. 182, 1872, Exp. 1, fj. 141

39 P. GROSSI, El orden jurídico medieval, Marcial Pons Ediciones Jurídicas y Sociales, Madrid 1996, 251 pp., 214.

40 P. GROSSI, El orden jurídico medieval..., cit. 214.

41 P. GROSSI, El orden jurídico medieval..., cit. 214.

42 AHPC, Esc. 2, Leg. 182, 1872, Exp. 1, fj. 142.

43 Sobre la conformación del Derecho Canónico Grossi señala dos elementos por un lado el ius divinum y por otro el ius humanus. El primero "compuesto por pocas reglas esenciales constitucionales [...], mientras que el segundo se caracteriza por consistir en un "enorme conjunto de reglas acumuladas durante la vida histórica de la Iglesia". P. GROSSI, El orden jurídico medieval..., cit., 133.

44 P. GROSSI, El orden jurídico medieval..., cit., 213.

45 P. GROSSI, El orden jurídico medieval..., cit., 213. 


\section{El Concilio de Trento como fuente normativa del derecho canónico}

Si bien una de las fuentes primordiales del derecho canónico es la costumbre, que fue expresamente considerada por el fiscal eclesiástico, la normativa tridentina se encuentra presente, implícita e explícitamente, en esta causa por tierras. Precisamente, la resolución del obispo se basó en la regulación normativa del Sacrosanto Concilio de Trento. Para ser más precisos, en la sesión -25, capítulo tercero, decreto de reforma del Concilio de Trento.

Como bien ha señalado López Lamerain este concilio "estuvo destinado tanto a reforzar el dogma católico -y así hacer notar el error de las herejías- como a iniciar la tan anhelada renovación de la Iglesia" ${ }^{\$ 4}$. Si bien es cierto que se ha caracterizado la problemática tratada en Trento como predominantemente eurocentrista, lo que se refuerza con la "la ausencia tanto de los prelados como de los temas religiosos hispanoamericanos en Trento" ${ }^{47}$, las disposiciones tridentinas no tardaron en arribar a la América española. En este sentido, debe tenerse en cuenta tanto la real cédula de Felipe II de 1564 como la labor de los concilios provinciales ${ }^{48}$. No obstante los esfuerzos llevados adelante en los concilios mexicano (1565) y limense (1567) “diversas dificultades hicieron que sus disposiciones pronto cayeran en desuso, y que su aplicación no resultase fructífera"49. Sin negar los desafíos que representó para Trento la propia configuración de la américa colonial, el análisis de esta problemática excede la finalidad de este artículo.

Para comprender cómo la sesión 25, capítulo tercero, decreto de reforma del Concilio de Trento, citada por el obispo, comparte el carácter dúctil e instrumental del derecho canónico se requiere un análisis de la misma. En este apartado, la normativa tridentina advertía la necesidad de emplear con precaución estas medidas a los fines de evitar que "se mezclen en esto los magistrados civiles" ${ }^{50}$. La necesidad de cautela se explica a partir del peligro que implicaba una potencial intromisión de un magistrado

46 M. C. LÓPEZ LAMERAIN, El concilio de Trento y Sudamérica: aplicaciones y adaptaciones en el III concilio limense, Anuario de Historia de la Iglesia en Chile 29 (2011) 15-32, 3.

47 E. TÁNACS, El Concilio de Trento y las iglesias de la América española: la problemática de su falta de representación, Fronteras de la Historia 7 (2002), 117-140, 118.

48 A los fines de tornar efectivos los reales decretos los concilios provinciales fueron considerados como los mecanismos más idóneos. En este sentido López Lamerían señala que "el Concilio de Trento había determinado que mediante la realización de estas reuniones se daría mejor curso a la reforma de la Iglesia en todas las localidades". M. C. LÓPEZ LAMERAIN, El concilio de Trento y Sudamérica..., cit., 6.

49 M. C. LÓPEZ LAMERAIN, El concilio de Trento y Sudamérica..., cit., 7. 
civil y por ende la configuración de un mixti fori. El foro mixto se configuraba si del delito cometido emergía una ofensa "a la sociedad civil i a la eclesiástica, corresponde [correspondiéndole] el juicio i castigo de ellos a uno i otro juez"51.

Pero más allá de los riesgos de caer en un caso de jurisdicción mixta, las disposiciones del concilio profundizan el papel que la excomunión jugaba en el ámbito canónico. En esta dirección, las normas enfatizan que la excomunión cumplía un rol preponderante, siendo considerada como el "nervio de la disciplina eclesiástica" 52 . Justamente, por esa función medular de su mal empleo emergieron nocivas consecuencias ya que se "fulmina temerariamente o por causas leves, más se desprecia que se teme, y más bien causa daño que provecho" ${ }^{53}$.

Estas últimas consideraciones sobre el perjuicio de un abuso de la excomunión permiten comprender el razonamiento del fiscal eclesiástico y del obispo, quienes coinciden en la necesidad de interpelar nuevamente al escribano y de valorar prudencialmente el valor de lo perdido. De esta manera, se cumple con el mandato de la subsidiariedad y se evita aplicar una pena tan relevante en casos de pérdida de un objeto cuyo valor no fuera relevante. Por último, la normativa tridentina reflexiona sobre la abstención de estas medidas, ya sea a lo largo de una causa o bien en su conclusión "siempre que pudieren de propia autoridad poner en práctica la ejecución real o personal”54.

Lamentablemente, en el expediente no hay más referencias sobre esta solicitud de excomunión por lo que resulta imposible ahondar en el proceso relativo a su imposición $^{55}$ o en las repercusiones que la imposición de esta pena hubiese podido generar en los excomulgados.

No obstante la diferencia temporal, es importante tener presente que Benito Moya ha señalado para Córdoba del Tucumán durante el período colonial que “en los conflictos jurisdiccionales las autoridades civiles parecen [cían] no prestarle importan-

51 J.DONOSO, Instituciones de Derecho Canónico Americano..., cit., 343.

52 CONCILIO DE TRENTO, El Sacrosanto y Ecuménico Concilio de Trento..., cit., 396.

53 CONCILIO DE TRENTO, El Sacrosanto y Ecuménico Concilio de Trento..., cit., 396.

54 CONCILIO DE TRENTO, El Sacrosanto y Ecuménico Concilio de Trento..., cit., 396.

55 En su investigación sobre el rol de la escritura en términos de disciplina miento social, Benito Moya desarrolla la metodología en materia de imposición de la pena. A los fines de lograr una disciplina en los miembros de una sociedad confesional la comunicación de la imposición de la pena era de vital importancia. Respecto a este punto el autor destaca el rol de "las lecturas en alta voz en misa mayor el ofertorio y fijar los autos en las puertas de las iglesias". S. BENITO MOYA, “Nadie le quite pena de excomunión mayor"..., cit. 29. A esto debemos sumarles las tablillas de excomunión en las que se inscribían los nombres de los excomulgados. Esta inscripción permitía identificar a "quiénes no podían entrar al templo durante las celebraciones litúrgicas [...] y a "quiénes se debía evitar para mayor escarnio público S. BENITO MOYA, “Nadie le quite pena de excomunión mayor”..., cit. 29. 
cia cuando cae [caía] sobre ellos y resisten [resistían], sin embargo, tarde o temprano luchan [ban] para que se les absuelva [absolviera]" ${ }^{\prime 6}$. A la par del caso de los magistrados, la solicitud de absolución es algo que se proyectó más allá de la vida de quien la sufriera, así "ya difuntos, son sus deudos quienes lo solicitan a través de las indulgencias que prodiga la Iglesia"57. Si bien las reflexiones del autor son propias del mundo colonial, creemos que, si a pesar de la fuerte impronta que la religión tenía en este universo, quienes la sufrían no se preocupaban ya que podrían apelar, por sí o mediante sus parientes, a la absolución; esta tendencia es algo que puede predicarse aún más en un contexto temporal en el que el "deslizamiento de una sociedad sacralizada hacia una sociedad secularizada implicó la redefinición del lugar que debía ocupar la Iglesia”58.

\section{De prácticas a codificación procesal}

A los fines de divisar cómo en las últimas décadas del siglo XIX las autoridades eclesiásticas sufrieron una suerte de desplazamiento en el ámbito de la administración de la justicia civil, proponemos una aproximación comparativa. Esta consiste en un cotejo entre una de las obras de práctica forense con mayor circulación en el espacio cordobés, e igualmente citada en nuestro expediente de análisis, y la normativa procesal sancionada en Córdoba por entonces.

Durante la apertura de las sesiones legislativas del año 1871, el ministro de hacienda, Garzón, informó el nombramiento de una comisión cuya tarea consistiría en "proyectar la organización de los tribunales así como un Código de Procedimientos ${ }^{59 "}$. De la lectura del mensaje se advierten cuáles eran las dificultades que emergían de la praxis local judicial, entre las que destacaba "la inaplicabilidad racional entre antiguas disposiciones legales con los usos y costumbres actuales”. Se esperaba que la nueva legislación terminara con "cuestiones inútiles en la práctica, [y que] armonizara en lo posible la brevedad de los juicios en el conocimientos de la verdad jurídica”60.

Respecto al conflicto que representaba la coexistencia de estas antiguas disposiciones con los nuevos usos y costumbres emergentes, son numerosas las pesquisas que

56 S. BENITO MOYA, “Nadie le quite pena de excomunión mayor”...., cit. 22.

57 S. BENITO MOYA, “Nadie le quite pena de excomunión mayor”...., cit. 38.

58 M. GALLARDO, Clero secular y territorialización parroquial..., cit., 88.

59 A. I. FERREYRA, Mensajes de los gobernadores de Córdoba a la legislatura, Tomo III, (1871-1885), Centro de Estudios Históricos Prof. Carlos S. A. Segreti, Córdoba 1997, 34.

60 A. I. FERREYRA, Mensajes de los gobernadores..., cit., 34. 
reflexionan en torno a persistencia de la cultura jurídica colonial de manera simultánea a la construcción de los diversos instrumentos normativos en los territorios provinciales del entonces territorio argentino.

En ese sentido, se ha señalado que en materia de praxis judicial la doctrina práctica era el soporte a partir del cual se construyó la praxis judicial legal cordobesa. Específicamente, en el caso que planteamos como objeto de estudio de este trabajo, se ha advertido la referencia de autores como "Eugenio Tapia, Manuel Antonio De Castro, Miguel Esteves Seguí, Marcos Gutiérrez, Joaquín Escriche, así como a obras típicas del Antiguo Régimen como la Curia Philipica de Juan de Hevia Bolaños”61. En materia de legislación, en esta misma causa se invocaron normativas propias del orden jurídico colonial “las Partidas, Novísima Recopilación, el Derecho Romano, [y el] Concilio de Trento" ${ }^{62}$. Precisamente, es esta última referencia normativa la que justifica una reflexión en torno a "la existencia de fronteras entre la religión y las prácticas procesales en Córdoba" ${ }^{3}$.

En términos de las transformaciones normativas en materia procesal, la sanción y entrada en vigencia de la Ley de Enjuiciamiento Civil de $1875^{64}$ es uno de los cambios más relevantes junto con la entrada en vigencia de la Ley Orgánica de Tribunales y el Código de Procedimientos en lo Civil y Comercial, en $1897^{65}$. Sobre el impacto de la primera de estas leyes el gobernador Rodríguez, en ocasión de la apertura de las sesiones legislativas de 1876, expresó que "Un nuevo código (...) ha reemplazado el embarazoso, complicado y dispendioso procedimiento, establecido para la tramitación de los juicios, por leyes y prácticas que nos vienen rijiendo desde tiempos remotos”66.

Es interesante reflexionar en torno al significado del concepto código, ya que si bien el instrumento no se titula de esta manera hay ciertos rasgos de la noción moderna

61 P. CACCIAVILLANI, De propiedad comunal..., cit., 74.

62 P. CACCIAVILLANI, De propiedad comunal..., cit., 74.

63 P.CACCIAVILLANI, De propiedad comunal..., cit., 74.

64 La ley fue sancionada el 13 de octubre de 1875 y su entrada en vigencia fue a parte del 1 de enero de 1876 . No obstante las necesidades de economía y celeridad procesal que esta ley trató de satisfacer, su modificación no tardaron en materializarse. En 1879 en gobernador del Viso expresó en la apertura de la asamblea legislativa que se abstenía "de llevar a vuestro seno algunas modificaciones a las leyes actuales del procedimiento civil y penal [...] Debido a que era de su personal conocimiento que el [...] Superior Tribunal de Justicia tiene [tenía] preparados trabajos al respecto".

65 Sobre este punto es interesante mencionar que en el texto que antecede la propia ley de enjuiciamiento en el artículo 3 se establecia que el Poder Ejecutivo mandaría a imprimir las leyes de Organización de los Tribunales y Enjuiciamiento Civil a los fines de formar un solo cuerpo. Será mediante la ley 1419 la disposición que apruba los proyectos de ley organica de tribuanes y el código de procedimientos en los civil y comercial las cuales entraron en vigencia el 1 de enero de 1897.

66 A. I. FERREYRA, Mensajes de los gobernadores..., cit., 87. 
de código en su contenido. Especialmente, la cláusula derogatoria "que abroga todo el derecho precedente sobre la materia por el regulada y por ello no integrable con materiales jurídicos vigentes" ${ }^{67}$. En el artículo 713 de la Ley de Enjuiciamiento Civil se advierte la voluntad derogatoria de la nueva normativa al establecer "quedan derogadas todas las leyes y disposiciones anteriores relativas al enjuiciamiento civil y mercantil en todo lo que sea contraria a la presente" ${ }^{\$ 68}$. Igualmente, la Ley 1419 que aprobó la Ley Orgánica de los Tribunales y Código de Procedimiento en lo Civil y Comercial, estableció que desde la entrada en vigor de estos instrumentos quedaban “desde esa fecha derogadas todas las leyes que a ellas se opongan" ${ }^{\prime 9}$.

Este tipo de cláusulas, desde lo formal, pretendían consagrarse como una vía de escape de aquellas prácticas y procedimientos complejos que bien retrata el mensaje del Gobernador. Justamente, nuestro caso de estudio contiene un interesante ejemplo de este tipo de prácticas; nos referirnos a la excomunión como un tipo de "disciplinamiento de las conciencias [a partir de ] formas impensadas de obediencia no atribuibles solamente al poder político y sus resortes eclesiásticos, sino también a un proceso a nivel celular entre la propia feligresía"70.

Para poder apreciar cómo las normas que regulan la práctica del foro fueron materializando el desplazamiento del poder de la religión en la administración de justicia $\mathrm{y}$, de ese modo, vislumbrar el fin de prácticas remotas, proponemos un cotejo entre el Prontuario de Práctica Forense del Manuel Antonio De Castro y la nueva normativa procesal provincial. La selección de la obra se justifica tanto porque ha sido expresamente citada en el caso de estudio como por su impronta. En esta dirección Abásolo señaló que "el libro circuló por todas las provincias argentinas además de "su asiduo empleo en la de Córdoba"71. El resultado de su efectiva circulación entre quienes transitaban por los tribunales se tradujo en que el mismo fuera "reputado entre los [libros] de mayor aceptación en los estrados del país y como una de las más caracterizadas expresiones

67 G. TARELLO, Cultura jurídica y política del derecho, Fondo de Cultura Económica, Ciudad de México 1995, 439 pp., 39.

68 Ley de Enjuiciamiento Civil de 1875, en Leyes de la Provincia de Córdoba Leyes N 671 a 717, Año 1871 a 1875, Tomo IV, Córdoba, Imp. Pablo Aubinel \& Cia, 1916, 260.

69 Ley 1419

70 S. BENITO MOYA, “Nadie le quite pena de excomunión mayor”...., cit. 5.

71 E. ABÁSOLO, Un jurista patrio en el tránsito hacia la cultura de la codificación: Manuel Antonio De Castro y su Prontuario de Práctica Forense, en Bastante más que "degradantes andrejos de nuestra pasada esclavitud" Fragmentos sudamericanos de la pervivencia de la cultura jurídica indiana durante el siglo XIX, Instituto de Investigaciones de Historia del Derecho, Buenos Aires 2014, 18-36. 22. 


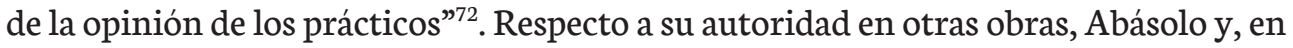
especial consideración al foro cordobés, destaca para la década de 1860 que la obra "se asimiló en el foro cordobés a la del febrero Novísimo de Tapia y a la de los Apuntamientos del Conde de la Cañada"73.

A partir de la lectura de la obra de De Castro se advierte la importancia de las regulaciones en materia de autoridades eclesiásticas, lo que nos señala que en la praxis legal no era poco frecuente toparse con estas autoridades. Existe un especial tratamiento de la recusación de jueces, lo que daba lugar a la intervención de autoridades, como el promotor fiscal eclesiástico y el obispo Metropolitano. Las referencias a autoridades eclesiásticas en materia de administración de justicia se encuentran también diseminadas en diferentes apartados del texto. Hemos advertido en su tratado, específicamente en los capítulos I, II, III, V, VI, IX, X, XI y XII ${ }^{74}$, disposiciones relativas a jueces eclesiásticos.

Ahora bien, de la lectura de la Ley de Enjuiciamiento Civil, la Ley Orgánica de Tribunales y Código de Procedimientos Civil y Comercial ${ }^{75}$ emerge que quedaron atrás las referencias a la autoridad eclesiástica,salvo en materia de prueba testimonial ${ }^{76}$. Estas transformaciones se comprenden a la luz del contexto político de aquel entonces, ya que a finales de la década del 1870 comenzaron a aflorar las controversias entre el Estado y la Iglesia. En esta dirección, Cucchi ha señalado como un factor clave la irrupción del Partido Autonomista, ya que este "hizo de la agenda laicista un aspecto importante

72 E. ABÁSOLO, Un jurista patrio..., cit., 24.

73 E. ABÁSOLO, Un jurista patrio..., cit., 24.

74 Capítulo I: Del juicio en general y de las personas que intervienen en él; capítulo III: orden y forma del juicio civil en primera instancia; capítulo V: orden y forma del juicio civil en segunda instancia, ó en grado de súplica; capítulo VI: del recurso de súplica; capítulo IX: de los recursos de fuerza; capítulo $\mathrm{X}$ : del recurso de fuerza en no otorgar la apelación; capítulo XI: Del recurso de fuerza en no otorgar la apelación; capítulo XII: de la recusación de jueces superiores é inferiores, asesores, relatores y escribanos. M. A. DE CASTRO, Prontuario de practica forense, Imprenta de la Independencia, Buenos Aires 1834, 263 pp.

75 Es importante señalar que el silencio de la ley en esta materia no es un impedimiento para que un católico pudiese recurrir a la autoridad eclésiastica mediante el derecho canónico. Será objeto de futuras investigaciones analizar el efecto derogatorio de estas leyes a la luz de los expedientes judiciales.

76 Ley de Enjuiciamiento civil: Art. 162 Toda persona presentada como testigo, está obligada a comparecer ante el Juez a pretar su declaración, salvo el caso de imposibilidad. Exceptuándose los primeros magistrados de la Nación y de la Provincia, los Ministros, los prelados eclesiásticos, los individuos del Senado, del clero, los del Congreso Nacional y Cámaras Provinciales, los de los tribunales superiores, los Jueces y los jefes mitilatres desde Coronel inclusive; los cuales prestarán sus declaraciones por medio de informe. Las mujeres honestas y personas septuagenarias no serán obligadas a comparecer al Juzgado para declarar, debien ser examinadas en su misma casa. Ley orgánica de los Tribunales y Código de Procedimientos en los civil y comercial: Art 321 Toda persona propuesta como testigo, estáobligada a comparecer ante el juez o tribunal a prestas su declaración, salvo el caso de imposibilidad física y a excepción de los primeros magistrados de la nación o de las provincias, sus ministros, los prelados, los miembros del cabildo eclesiástico, los de las cámaras nacionales o provinciales y de los tribunales de justicia, los jueces letrados y los jueces militares, desde el coronel inclusive; los cuales declararán por medio de informe expresando que lo hace bajo juramento. La contraparte podrá presentar pliego de repreguntas. 
de su programa"77. Lo que generó un conflicto tanto con la Iglesia - y sus autoridades como con los sectores afines al catolicismo, quienes interpretaron su gestión "como una negativa del gobierno a brindar su concurso a las instituciones eclesiásticas y [...] como un avance de la autoridad civil sobre la religiosa"78.

Creemos que este desplazamiento de las autoridades eclesiásticas en la administración de justicia contribuye al análisis de "los procesos de secularización en plural"79. Esto implica, por un lado, tomar distancia de aquellas posturas que lo abordan de una manera teleológica; y por otro, considerar que este "redefiniría el rol que debía cumplir el clero en una sociedad secular-moderna, perdiendo, desde este punto de vista, su rol tradicional" ${ }^{\prime 0}$ pero no por ello protagonismo en diferentes áreas de la vida.

\section{Reflexiones finales}

La segunda mitad del siglo XIX trajo una serie de cambios relevantes en términos legales. A la par de los códigos de fondo, en el espacio cordobés la Ley de Enjuiciamiento Civil de 1875, primero, y la Ley 1419 de 1897, después, marcaron grandes transformaciones en la praxis legal. Considerando las reflexiones de diferentes hombres de gobierno, pudimos advertir que los cambios que se pretendían concretar mediante estas leyes estaban orientados, principalmente, a resolver la falta de celeridad y la continuidad de ciertas prácticas de tiempos remotos. Para el estudio de la continuidad de estas prácticas, propusimos un expediente judicial y advertimos las huellas del orden jurídico pretérito mediante citas de autores como De Castro, Escriche, Tapia, entre otros. En esta misma línea de continuidad, la invocación de normativas como Las Partidas, La Novísima Recopilación y el Concilio de Trento, jugaron un papel rotundo.

En el mismo expediente judicial pudimos divisar y analizar un tipo de práctica procesal concreta: la solicitación de excomunión. Medida que demandaba necesariamente la actuación conjunta de la jurisdicción eclesiástica y secular. Este auxilio solicitado motiva la reflexión en torno a los límites entre la jurisdicción civil y la eclesiástica en el espacio local. La invocación de la medida en el año 1866, como único remedio para

\footnotetext{
$\left(\frac{10}{10}\right.$

77 L. CUCCHI, Estado, Iglesia y partidos en los inicios del poder autonomista en Córdoba, Argentina (1877-1880), Iberoamericana, XIV 54 (2014), 54-77, 60.

78 L. CUCCHI, Estado, Iglesia y partidos..., cit., 64.

79 R. DI STEFANO, La excepción argentina. Construcción del Estado y de la Iglesia en el siglo XIX, PROCESOS Revista Ecuatoriana de Historia, 40 (2014) 91-114, 94.

80 M. GALLARDO, Clero secular y territorialización parroquial..., cit., 88.
} 
recuperar el expediente robado, nos permite considerar que en la sociedad cordobesa de la segunda mitad del siglo XIX, la religión seguía jugando un papel relevante.

A partir de la lectura de obras canónicas, advertimos las serias consecuencias, tanto públicas como privadas, que acarreaba la excomunión. Lo que podría llevarnos a pensar a la excomunión como una estrategia procesal, dado su capital simbólico en una sociedad católica. No obstante, a partir de los estudios especializados en el mundo colonial pudimos apreciar una conducta muy diferente de la esperada por sus destinatarios. En esta dirección, algunos autores han señalado no solo la falta de interés de las autoridades civiles sino su contumacia frente a la imposición de la pena espiritual sobre ellos mismos.

En este juicio por tierras advertimos que la aplicación de la pena se vio condicionada por los requerimientos que exigía la norma tridentina para su procedencia, ya que esta pena era el "nervio de la disciplina eclesiástica"81; también lo estuvo por las actitudes que tomaron tanto el fiscal eclesiástico como el obispo. La subsidiariedad de la medida juntoa la apelación al prudente arbitrio del prelado, deben leerse y comprenderse en el contexto del derecho canónico en el que la relaxatio legis formaba parte de la matriz misma de este orden normativo. Quizás es por ello que en el expediente no hay más referencias sobre esta solicitud de excomunión, por lo que resulta imposible ahondar en el proceso relativo a su imposición. Esta paralización de la medida podría indicarnos que el rol de la religión no era tan relevante, en el sentido que la amenaza de la pena no era efectiva para recuperar el objeto en cuestión, o que el valor de la cosa perdida no ameritaba su procedencia.

Habernos topado con este tipo de prácticas en la segunda mitad del siglo XIX nos permitió identificar una zona de persistencia y continuidad de la cultura jurídica indiana, en la que no había una distinción tajante entre el derecho y religión. Desde una perspectiva formal, esta situación persistió entrado el siglo XIX, un vez que se dieron los cambios tan esperados en materia de legislación procesal. En otras palabras, los límites difusos entre religión y derecho persistentes en los libros y en la práctica forense, se concretarán a partir de la emergencia de las codificaciones procesales. Especialmente, a partir de su marcado rol derogatorio de la normativa precedente.

Con el objetivo de indagar sobre los límites entre las fronteras de la jurisdicción civil y eclesiástica propusimos una comparación entre el Prontuario de Práctica Forense de De Castro y la Ley de Enjuiciamiento Civil y la Ley 1419. Como resultado, advertimos

81 CONCILIO DE TRENTO, El Sacrosanto y Ecuménico Concilio de Trento..., cit., 396. 
el fuerte desplazamiento de las autoridades eclesiásticas en materia de administración de justicia, aspecto comprensible si consideramos la marcada laicidad que caracterizó la política cordobesa a partir de 1877.

\section{REFERÊNCIAS}

E. ABÁSOLO, Un jurista patrio en el tránsito hacia la cultura de la codificación: Manuel Antonio De Castro y su Prontuario de Práctica Forense, en Bastante más que "degradantes andrejos de nuestra pasada esclavitud" Fragmentos sudamericanos de la pervivencia de la cultura jurídica indiana durante el siglo XIX, Instituto de Investigaciones de Historia del Derecho, Buenos Aires 2014, 18-36.

A. AGÜERO, Castigar y perdonar cuando conviene a la república. La justicia penal de Córdoba, siglos XVII y XVIII, Centro de Estudios Políticos y Constitucionales, Madrid 2008, 488 pp.

A. AGÜERO, Las penas impuestas por el Divino y Supremo Juez. Religión y justicia secular en Córdoba del Tucumán (Siglos XVII y XVIII), Jahrbuch für Geschichte Lateinamerikas, 46 (2009) 203-30.

A. AGÜERO, Tradición jurídica y derecho local en época constitucional: El Reglamento para la Administración de justicia y policía en la campaña de Córdoba, 1856, Revista Historia del Derecho, 41 (2016) 1-43. http://www.scielo.org.ar/pdf/rhd/n41/n41a01.pdf

D. BARRIERA, Historia y Justicia. Política y sociedad en el Río de la Plata (Siglos XVI-XIX), Prometeo, Ciudad Autónoma de Buenos Aires 2019, 742 pp.

D. BARRIERA (comp.), Justicia y fronteras. Estudios sobre historia de la justicia en el Río de la Plata. (Siglos XVI-XIX), Universidad de Murcia / Servicio de Publicaciones / Red Columnaria, Murcia 2009, 244 pp.

S. BENITO MOYA, "Nadie le quite pena de excomunión mayor". Escritura expuesta y confesionalización en Córdoba del Tucumán durante la colonia, Documenta \& Instrumenta - Documenta Et Instrumenta, 18 (2020) 11-40. https://doi.org/10.5209/docu.68781

N. BERALDI, La implementación de la justicia de paz en la provincia de Córdoba. ¿Claves tradicionales en un mundo liberal?, Revista Historia del Derecho, 53 (2017) 1-22.http://www.scielo.org.ar/scielo.php?script=sci_arttext\&pid=S1853-17842017000100001\&lng=es\&nrm=iso\&tlng=es

P. P. CABRERA, Ex-alumnos célebres de la Universidad de Córdoba. Miguel Calixto Del Corro, Revista De La Universidad Nacional De Córdoba, 1 (2013) 3-109. https://revistas.unc.edu.ar/index.php/REUNC/article/view/4240

P. CACCIAVILLANI, De propiedad comunal a propiedad individual. El régimen jurídico de la propiedad en Córdoba 1871-1885. Tesis de doctorado, Facultad de Derecho y Ciencias Sociales, Universidad Nacional de Córdoba, Argentina. 2018.

B. CLAVERO, Religión y Derecho. Mentalidades y Paradigmas, Historia Instituciones Documentos, 11 (1984) 67-92.

CONCILIO DE TRENTO, El Sacrosanto y Ecuménico Concilio de Trento, traducido al idioma castellano por Ignacio López de Ayala con el texto latino corregido según la edición publicada en 1564, Imprenta de Don Ramón Martin Indar, Barcelona 1847, 440 pp. 
M. A. CORVA, Constituir el gobierno, afianzar la justicia. El poder judicial de la provincia de Buenos Aires (1853-1881), Prohistoria Ediciones / Instituto de Investigaciones de Historia del Derecho, Rosario 2014, 364 pp.

Ley de Enjuiciamiento Civil de 1875, en Leyes de la Provincia de Córdoba Leyes N 671 a 717, Año 1871 a 1875, Tomo IV, Imp. Pablo Aubinel \& Cia, Córdoba, 1916.

L. CUCCHI, Estado, Iglesia y partidos en los inicios del poder autonomista en Córdoba, Argentina (18771880), Iberoamericana, XIV 54 (2014), 54-77. https://core.ac.uk/reader/268403020

M. A. DE CASTRO, Prontuario de practica forense, Imprenta de la Independencia, Buenos Aires 1834, $263 \mathrm{pp}$.

N. DELLAFERRERA, Ministros y auxiliares de la justicia eclesiástica en Córdoba (1688-1888), Revista de Historia del Derecho, 25 (1997) 151-182.

Diccionario de Derecho Canónico arreglado a la Jurisprudencia Eclesiástica Española Antigua y Moderna, Librería de Rosa y Bouret, París 1853, 1113 pp. http://www.adabi.org.mx/vufind/Record/118880

R. DI STEFANO, La excepción argentina. Construcción del Estado y de la Iglesia en el siglo XIX, PROCESOS Revista Ecuatoriana de Historia, 40 (2014) 91-114. http://hdl.handle.net/10644/4567

J. DONOSO, Instituciones de Derecho Canónico Americano, Imprenta y librería del Mercurio, Valparaíso $1848,818 \mathrm{pp}$.

A. I. FERREYRA, Mensajes de los gobernadores de Córdoba a la legislatura, Tomo III,(1871-1885), Centro de Estudios Históricos Prof. Carlos S. A. Segreti, Córdoba 1997.

M. GALLARDO, Clero secular y territorialización parroquial en la diócesis de Córdoba, 1875-1925 Prácticas y poder pastoral en el marco del proceso de romanización de la Iglesia y modernización del Estado, Universidad Nacional de la Plata, Facultad de Humanidades y Ciencias de la Educación, Secretaría de Posgrado, La Plata 2016, 942 pp.http://www.memoria.fahce.unlp.edu.ar/tesis/te.1373/te.1373.pdf

P. GROSSI, El orden jurídico medieval, Marcial Pons Ediciones Jurídicas y Sociales, Madrid 1996, $251 \mathrm{pp}$.

A. LEVAGGI, La codificación del procedimiento civil en la Argentina, Revista Chilena de Historia del Derecho 9 (1983) 211-47. DOI: 10.5354/0719-5451.2012.25693

J. LIRA. Prontuario de los Juicios o tratado de los procedimientos judiciales, Librería Central de Mariano Servant, Santiago de Chile 1895.

M. C. LÓPEZLAMERAIN, El concilio de Trento y Sudamérica: aplicaciones y adaptaciones en el III concilio limense, Anuario de Historia de la Iglesia en Chile 29 (2011) 15-32. http://intushistoria.uai.cl/index. php/intushistoria/article/view/90

J. OTADUY, Las fuentes del derecho canónico, en J. P. ALCOCER MENDOZA (Coor.), Temas Actuales de Derecho Canónico, Universidad Nacional de México, Instituto de Investigaciones jurídicas, México 2016, 201-220. https://archivos.juridicas.unam.mx/www/bjv/libros/9/4239/1.pdf

E. TÁNACS, El Concilio de Trento y las iglesias de la América española: la problemática de su falta de representación, Fronteras de la Historia 7 (2002), 117-140. 
G. TARELLO, Cultura jurídica y política del derecho, Fondo de Cultura Económica, Ciudad de México $1995,439 \mathrm{pp}$.

T. TAU ANZOATEGUI, El Jurista en el Nuevo Mundo. Pensamiento. Doctrina. Mentalidad, Global Perspectives on Legal History, Max Planck Institute für europäische Rechtsgeschichte, Frankfurt 2016, 270 pp.http://dx.doi.org/10.12946/gplh7

M. R. TORRES JIMÉNEZ, El castigo del pecado: excomunión, purgatorio, infierno, en Los Caminos de la Exclusión, en E. López Ojeda (Coor.), La Sociedad Medieval: Pecado, Delito y Represión, Instituto de Estudios Riojanos, Logroño 2012, 245-307. https://ruidera.uclm.es/xmlui/bitstream/handle/10578/2981/ fi_1365097607-separata\%20excomunionpurgatorio.pdf?sequence=1\&isAllowed=y 